\title{
Investigation of Genetic Alterations in Congenital Heart Diseases in Prenatal Period
}

\author{
Emine Ikbal Atli ${ }^{1}$ Engin Atli ${ }^{1} \quad$ Sinem Yalcintepe ${ }^{1} \quad$ Selma Demir $^{1} \quad$ Rasime Kalkan $^{2}$ Cisem Akurut ${ }^{1}$ \\ Yasemin Ozen ${ }^{1}$ Hakan Gurkan ${ }^{1}$ \\ 1 Department of Medical Genetics, Faculty of Medicine, Trakya \\ University, Edirne, Turkey \\ 2 Department of Medical Genetics, Faculty of Medicine, Near East \\ University, Nicosia, Cyprus

\begin{abstract}
Address for correspondence Emine Ikbal Atli, PhD, Department of Medical Genetics, Faculty of Medicine, Trakya University, Balkan Campus, Highway D100, 22030 Edirne, Turkey

(e-mail: emine.ikbal@gmail.com; eikbalatli@trakya.edu.tr).
\end{abstract}

Glob Med Genet 2022;9:29-33.

\begin{abstract}
Keywords

- CHD

- aCGH

- genetic testing

- congenital heart disease

The prenatal diagnosis of congenital heart disease (CHD) is important because of mortality risk. The onset of CHD varies, and depending on the malformation type, the risk of aneuploidy is changed. To identify possible genetic alterations in CHD, G-banding, chromosomal microarray or if needed DNA mutation analysis and direct sequence analysis should be planned.

In present study, to identify genetic alterations, cell culture, karyotype analysis, and single nucleotide polymorphism, array analyses were conducted on a total 950 samples. Interventional prenatal genetic examination was performed on 23 (2, 4\%, 23/950) fetal CHD cases. Chromosomal abnormalities were detected in 5 out of 23 cases $(21,7 \%)$. Detected chromosomal abnormalities were $10 q 23.2$ deletion, trisomy 18, 8p22.3-p23.2 deletion, 8q21.3-q24.3 duplication, 11q24.2q24.5 (9 Mb) deletion, and 8 p22p12 $(16.8 \mathrm{Mb})$ deletion. Our study highlights the importance of genetic testing in CHD.
\end{abstract}

\section{Introduction}

Congenital anomalies are the important factor for infant death and congenital heart disease (CHD) that account for 30 to $50 \%$ of these deaths. ${ }^{1}$ Therefore, prenatal diagnosis and management of fetal cardiac abnormalities are important because they provide information before birth and gives chance to decision of treatment options before and after delivery and plan for specific health essentials at birth. There is a few information which shows interaction between prenatal diagnosis and morbidity or mortality of affected fetuses. $^{2}$ Screening of fetal cardiac anomalies has been applied between 18 and 22 weeks of gestation. ${ }^{3}$

The onset of fetal arrhythmias, myocarditis/cardiomyopathy, heart failure, valvular insufficiency or obstruction, and cardiac tumors varies. But on the other side, prenatal detec- tion of small ventricular or atrial septal defects, minor valve lesions, partial anomalous pulmonary venous connection, and coronary artery anomalies is not possible. According to the study, sensitivity and specificity of first trimester ultrasound examination for detection of major CHD were 85 (95\% confidence interval [CI]: 78-90) and 99\% (95\% CI: 98-100), respectively. ${ }^{4}$

Fetal echocardiography has been suggested according to the American Heart Association, the American Society of Echocardiography, and the Pediatric and Congenital Electrophysiology Society guidelines. ${ }^{3}$ To be able to identify genetic abnormalities, fetal genetic assessment has been indicated in fetuses with cardiac defects. ${ }^{5-10}$ In general, abnormal karyotype is detected in affected cases. ${ }^{11}$ Depending on the malformation type, the risk of aneuploidy varies. ${ }^{3}$ Aneuploidy risk was 46 to $73 \%$ in atrioventricular septal defect, 19 to $78 \%$ in received

August 3, 2021

accepted after revision

September 9, 2021

published online

November 9, 2021
DOI https://doi.org/

$10.1055 / \mathrm{s}-0041-1736566$.

ISSN 2699-9404.
(C) 2021. The Author(s).

This is an open access article published by Thieme under the terms of the Creative Commons Attribution License, permitting unrestricted use, distribution, and reproduction so long as the original work is properly cited. (https://creativecommons.org/licenses/by/4.0/)

Georg Thieme Verlag KG, Rüdigerstraße 14, 70469 Stuttgart, Germany 
Table 1 CHDs and associated genetic syndromes

\begin{tabular}{|c|c|c|c|c|}
\hline Genetic abnormality & Genetic test & Type of CHD & $\begin{array}{l}\% \text { Affected } \\
\text { by CHD }\end{array}$ & Associated genes \\
\hline Trisomy 21 & $\begin{array}{l}\text { FISH } \\
\text { CMA }\end{array}$ & ASD, VSD, AVCD, TOF & $40-50$ & $\begin{array}{l}\text { 3rd copy of chromosome } 21 \text {; } \\
\text { unbalanced translocation }\end{array}$ \\
\hline Trisomy 13 & $\begin{array}{l}\text { FISH } \\
\text { CMA }\end{array}$ & $\begin{array}{l}\text { ASD, PDA, VSD, } \\
\text { pulmonary atresia with CHD }\end{array}$ & $60-80$ & $\begin{array}{l}\text { 3rd copy of chromosome 13; } \\
\text { unbalanced translocation }\end{array}$ \\
\hline Trisomy 18 & $\begin{array}{l}\text { FISH } \\
\text { CMA }\end{array}$ & $\begin{array}{l}\text { ASD, VSD, PDA, CoA, } \\
\text { bicuspid aortic valve, } \\
\text { complex CHD }\end{array}$ & $60-80$ & 3rd copy of chromosome 18 \\
\hline $\begin{array}{l}\text { Monosomy X } \\
\text { (Turner syndrome) }\end{array}$ & $\begin{array}{l}\text { FISH } \\
\text { CMA }\end{array}$ & $\begin{array}{l}\text { CoA, BAV, AS, } \\
\text { partial anomalous pulmonary, } \\
\text { venous return, HLHS }\end{array}$ & $23-50$ & $\begin{array}{l}\text { Partial or incomplete absence } \\
\text { of } 1 \mathrm{X} \text { chromosome } 45 \mathrm{X}\end{array}$ \\
\hline $\begin{array}{l}\text { DiGeorge syndrome } \\
\text { (chromosome } \\
22 q 11.2 \text { deletion) }\end{array}$ & FISH, CMA & $\begin{array}{l}\text { IAA type B, } \\
\text { aortic arch anomalies, } \\
\text { truncus, arteriosus, TOF }\end{array}$ & $70-75$ & 22q11.2 deletion \\
\hline Noonan syndrome & $\begin{array}{l}\text { Noonan } \\
\text { gene panel }\end{array}$ & PS, hypertrophic CM, ASD & $70-80$ & $\begin{array}{l}\text { RAS-MAPK pathway (KRAS, } \\
\text { SOS1, RAF1, NRAS, BRAF, } \\
\text { SCHOC2, CBL, RIT1) }\end{array}$ \\
\hline Alagille syndrome & CMA & PS, TOF & 90 & JAG1, NOTCH2 \\
\hline Holt-Oram syndrome & $\begin{array}{l}\text { Molecular } \\
\text { testing }\end{array}$ & HCM & 75 & TBX5 \\
\hline
\end{tabular}

Abbreviations: AVCD, atrioventricular canal defect; ASD, atrial septal defect; BAV, bicuspid aortic valve; CHD, congenital heart disease; CM, cardiomyopathy; CMA, chromosomal microarray; CoA, coarctation of the aorta; HCM, hypertrophic cardiomyopathy; PDA, patent ductus arteriosus; PS, pulmonic stenosis; TOF, tetralogy of Fallot; VSD, ventricular septal defect.

truncus arteriosus, 6 to $43 \%$ in double-outlet right ventricle/ conotruncal malformations, 5 to $37 \%$ in coarctation/arch interruption, 4 to $16 \%$ in tricuspid valve dysplasia, 7 to $39 \%$ in tetralogy of Fallot, $0 \%$ in heterotaxy/cardiosplenic syndromes, and $0 \%$ in transposition of great arteries. The most known genetic alteration is $22 \mathrm{q} 11$ deletion that was associated with several cardiac anomalies, including interrupted aortic arch, truncus arteriosus, ventricular septal defect, and tetralogy of Fallot. ${ }^{12}$ Genetic abnormalities can be identified by using Gbanding or chromosomal microarray. ${ }^{13,14}$ If these tests are normal and there is a positive family history of a similar cardiac defect or long QT syndrome and Noonan syndrome, DNA mutation analysis and direct sequence analysis should be planned to identify genetic alterations ( $\mathbf{- T a b l e ~ 1 ) . ~ A d v a n c e - ~}$ ment of technology, next-generation-based techniques like whole exome sequencing will be used to identify new genetic syndromes in fetuses suspected with CHD. ${ }^{15,16}$

\section{Methods}

A total 950 samples were collected prospectively between the years of 2014 to 2020 . The study population was referred for prenatal diagnosis for the suspicion of CHD risk. This study was approved by the Ethics Committee of the Faculty of Medicine, Trakya University, and all methods were performed in accordance with the relevant guidelines and regulations. Written informed consent was obtained from the parents of the CHD fetus. Results of fetal heart screening, maternal and gestational age, and extracardiac abnormalities were recorded. Evaluation of pregnancy was performed by Perinatology Unit, Department of
Obstetrics, and Trakya University Faculty of Medicine. Ultrasound examination was performed by physicians with prenatal ultrasound diagnostic qualifications using GE Voluson E8 (GE Healthcare, Lafayette, Colorado, United States), Philips iU22 (Philips, Copenhagen, Denmark), Siemens Acuson Sequoia 512 (SIEMENS, Munich, Germany), or S2000 (SIEMENS, Munich, Germany) color Doppler ultrasound with 2D/3D volume probe (frequency: 4, 0$8,0 \mathrm{MHz}$ ). All exams included a two-dimensional evaluation of cardiac structures with the "basic" (four-chamber view of the fetal heart) and the "extended basic" cardiac screening examination (views of the outflow tracts). Ductal and aortic arches position was evaluated by color Doppler. Cardiac situs, rhythm, venous inflow, atrial and ventricular chambers, atrioventricular and semilunar valves, and ventriculoarterial connections were assessed. ${ }^{17,18}$ According to our protocol, the results were classified as "normal" or "abnormal." The cases considered "abnormal" were undergone to a postnatal echocardiogram at the same hospital. We categorized the abnormal fetal heart according to complexity of the heart anatomical abnormalities in "complex," "significant," "minor," and "others." 19,20 Twenty-three pregnant women underwent fetal ultrasound examination and fetal heart screening at the mid-pregnancy stage.

\section{Fetal CHD Genetic Examination}

Amniotic fluid (20-30 mL) was drawn by Department of Obstetrics for cell culture, karyotype analysis, and single nucleotide polymorphism-array analysis. The specimens were sent to the laboratory for cell culture, and after that G-banding and karyotype analysis have been done by using a 
Table 2 Indications for fetal echocardiography of 23 fetuses with cardiac defects

\begin{tabular}{|l|l|}
\hline Indication & $\boldsymbol{n}(\%)$ \\
\hline $\begin{array}{l}\text { Suspicion of cardiac anomaly in a routine } \\
\text { scan }\end{array}$ & $12(56.52)$ \\
\hline Family history & $3(13.04)$ \\
\hline Extracardiac defect & $3(13.04)$ \\
\hline Complex & $5(21.73)$ \\
\hline
\end{tabular}

chromosome automatic analyzer (US PE Company). The karyotype was nomenclatured according to the International Cytogenetics International Nomenclature System (AKAS Karyotyper Genetic Diagnosis Assisted Karyotyping System, supported by Istanbul Technical University, Ministry of Science and Technology, Istanbul, Turkey). The statistical analyses were performed using SPSS Statistics version 19.0 (SPSS Inc, Chicago, Illinois, United States), and 2-tailed $p<0.05$ was considered statistically significant.

\section{Results}

A total $23(2,4 \%)$ out of 950 pregnancies were diagnosed as a fetal CHD by systemic ultrasound and fetal echocardiography (-Table 2). The mean age of the pregnant women was 28.3 years (range: 22-41) and the median gestational age at the time of ultrasound examination was 21.2 (range: 18-23).

The prenatal findings are summarized in - Table 3. Interventional prenatal genetic examination was performed for 23 $(2,4 \%, 23 / 950)$ fetal CHD cases. Among these, chromosomal abnormalities were detected in 5 out of 23 cases $(21,7 \%)$.

A total 22 (95.65\%) out of 23 fetuses with isolated cardiac malformations were delivered and alive at a mean follow-up of 38 (range: 1-120) months. Among the infants with isolated cardiac lesions delivered alive, conotruncal anomalies and univentricular lesions were the predominant types of defects. All fetuses with a prenatal diagnosis of isolated severe dysrhythmias are currently alive.

\section{Discussion}

Accuracy of antenatal diagnosis and the clinical impact of the antenatal recognition determines the capability of identifi- cation of fetal cardiac defects. Many cardiac anomalies are severe and couples do not continue to the pregnancy. But in our study population, the vast majority of our patients decided to continue their pregnancy after the diagnosis of fetal CHD. During the decision stage in general, the severity of the anomaly had an influence on the decision. In our study, there was no difference in the decision to terminate the pregnancy with an isolated anomaly compared with cases with multiple anomalies (20, 3 vs. $24,7 \%$ ). Whether the prenatal diagnosis of a cardiac malformation is beneficial for the affected infants has been the subject of many discussions. ${ }^{21}$ The incidence of prenatal CHD varies from 2, 4 to $54 \%{ }^{5,22-26}$ This variability was based on the performance of a systematic screening in each country. The number of CHD patients was lower than other study groups in the literature, and this was a limitation of our study. Statistical analyzes of our study population were made accordingly, due to the low number of abnormal cases. Because the number of abnormal cases are low and this was prevented, a more detailed statistical analyses of our study population. However, our chromosomal anomality rates were higher and also we have a higher incidence of complex cases. Here, we recommended that continuous efforts should be needed for prenatal screening programs of CHD. We believe that with the knowledge of these data, we can improve the outcomes of morbidity and mortality of children in our institution.

Patient 1 was 18 weeks pregnant and had a bilateral choroid plexus cysts and cardiac hyperechogenic focal findings on ultrasound examination. After array comparative genomic hybridization (aCGH) analyses, deletion of 10q23.2 region was detected. According to the literature, CHDs were associated with recurrent 10q22q23 deletion syndrome and partially overlapping distal 10q23.2.q23.31 microdeletions. ${ }^{27}$

BMPR1A gene plays a key role during the development of CHD in patients suffering from interstitial $10 \mathrm{q}$ deletions. Previous studies showed that BMPR1A was the highest ranked candidate gene for CHD. Cardiac specific deletion of BMPR1A (alk3) disrupts the cardiac morphogenesis in mice and causes the ventricular septum, trabeculation, and endocardial cushion. ${ }^{28}$

ALK3 was also important during the morphogenesis of atrioventricular valves and annulus fibrosus and studies

Table 3 The prenatal findings of 23 fetal CHD cases

\begin{tabular}{|l|l|l|}
\hline Patient age & Type of defect & Karyotype/aCGH results \\
\hline 25 & $\begin{array}{l}\text { Bilateral choroid plexus cyst, hyperechogenic focus in the } \\
\text { heart on US }\end{array}$ & $10 \mathrm{q} 23.2$ deletion \\
\hline 41 & Cystic hygroma, VSD in the heart, hyperechogenic bowel & Trisomy 18 \\
\hline 22 & $\begin{array}{l}\text { Left heart hypoplasia, VSD, cystic hygroma, posterior } \\
\text { fossa anomaly }\end{array}$ & $\begin{array}{l}8 \mathrm{p} 22.3-\mathrm{p} 23.2 \text { deletion, } \\
8 \mathrm{q} 21.3-\mathrm{q} 24.3 \text { duplication }\end{array}$ \\
\hline 24 & Dextrocardia & $11 \mathrm{q} 24.2 \mathrm{q} 24.5(9 \mathrm{Mb})$ deletion \\
\hline 28 & Hyperechogenic focus in the heart & $8 \mathrm{p} 22 \mathrm{p} 12(16.8 \mathrm{Mb})$ deletion \\
\hline
\end{tabular}

Abbreviations: aCGH, array comparative genomic hybridization; CHD, congenital heart disease; US, ultrasound; VSD, ventricular septal defect. 
demonstrated that inactivation of Alk3 in the atrioventricular canal myocardium causes abnormalities. ${ }^{29}$ This cardiac phenotype was consistent with our patients who carried a larger 10q deletions (atrioventricular septal defect [AVSD], atrial septal defect, VSD, and tricuspid insufficiency).

In a case who underwent amino synthesis at 18 weeks of gestation because of left heart hypoplasia, VSD, cystic hygroma, posterior fossa anomaly, we detected 8p22.3p23.2 deletion and 8q21.3-q24.3 duplication. Babies who carry 8p23 deletions do not develop any problem during pregnancy and delivered via normal birth. After delivery, they can be identified. In our study population, structural anomalies were detected as a result of ultrasound examination. According to the literature, heart defects developed in $75 \%$ of children with a terminal deletion of 8 p23 and $94 \%$ of those with an interstitial deletion. The GATA4 gene (GATA binding protein 4) was located proximal part of band 8p23.1 and responsible for heart conditions. ${ }^{30}$ Spectrum of heart defects varies. AVSD accounts for almost half of the heart conditions in children who carry an 8p23 deletion. Pulmonary stenosis, atrial septal defects, ventricular septal defects, hypoplastic left heart syndrome, and congenital diaphragmatic hernia were also reported during the 8p23 deletion. Newborn babies who have CHD may have respiratory distress and may require oxygen and/or breathing assistance. Surgery is necessary to repair the hole. According to the Wat studies interstitial 8p23 deletion and terminal 8p23 deletion were detected in affected cases. ${ }^{31}$ But on the other side there were limited literature information regarding the $8 \mathrm{q}$ duplication. In one series, 30 babies out of 33 were born with a heart defect. In another series, nine babies out of 20 were born with a duplication from 8q13-24 to 8qter had a heart defect. The typical heart defect in babies with $8 \mathrm{q}$ duplications is known as a conotruncal defect. Recombinant eight syndrome occurs in as many as two-thirds of babies. Conotruncal defects arise 5 to 6 weeks after conception when the heart is still an S-shaped tube with upper and lower bulges. ${ }^{32,33}$

In one patient, a right-located heart anomaly was reported in our study population. We detected 11q24.2q24.5 (9 Mb) deletion and this result was confirmed by aCGH analysis. When we compared the phenotype of our patient with literature that describes a new patient carrying the large interstitial $11 \mathrm{q}$ deletion who exhibits the Jacobsen syndrome (JBS; OMIM 147791) phenotype. To our knowledge, only five patients with an overlapping deletion in 11q24.3q25 have been reported. $^{34-38}$ Thrombocytopenia, developmental delay, $\mathrm{CHD}$, and short stature were the characteristic clinical findings of $11 \mathrm{q}$ deletion. ${ }^{39}$ The breakpoints are located to the distal to subband 11q23.3 and the deletion usually extends to the telomere and interstitial deletions rarely occurred within the JBS region. In our patient, 11q24.2q24.3 deleted region contains eight OMIM genes: ETS1, FLI1, SENCR, KCNJ1, KCNJ5, ARHGAP32 (RICS), TP53AIP1, and BARX2. ETS1 and FLI-1 were the members of the ETS family of transcription factors and ETS-1 plays an important role in a wide range of biological functions. Recent studies showed that ETS plays key role during the heart development in nonmammalian and mam- malian species. ${ }^{40-44}$ These findings indicated that ETS-1 should be a candidate gene for CHD in our patient. ${ }^{35}$

\section{Conclusion}

Prenatal diagnosis is important in CHD. After ultrasonic examination, genetic evaluation of pregnancy should be planned. Depending on the malformation type, the risk of aneuploidy varies. To identify possible genetic alterations, Gbanding, chromosomal microarray or if needed DNA mutation analysis and direct sequence analysis should be planned. Our study highlights the importance of genetic testing in CHD.

\section{Conflict of Interest}

None declared.

Acknowledgment

We would like to thank all of the participants in this study.

\section{References}

1 Heron M. Deaths: leading causes for 2014. Natl Vital Stat Rep 2016;65(05):1-96

2 Holland BJ, Myers JA, Woods CR Jr. Prenatal diagnosis of critical congenital heart disease reduces risk of death from cardiovascular compromise prior to planned neonatal cardiac surgery: a metaanalysis. Ultrasound Obstet Gynecol 2015;45(06):631-638

3 Donofrio MT, Moon-Grady AJ, Hornberger LK, et al; American Heart Association Adults With Congenital Heart Disease Joint Committee of the Council on Cardiovascular Disease in the Young and Council on Clinical Cardiology, Council on Cardiovascular Surgery and Anesthesia, and Council on Cardiovascular and Stroke Nursing. Diagnosis and treatment of fetal cardiac disease: a scientific statement from the American Heart Association. Circulation 2014;129(21):2183-2242

4 Rasiah SV, Publicover M, Ewer AK, Khan KS, Kilby MD, Zamora J. A systematic review of the accuracy of first-trimester ultrasound examination for detecting major congenital heart disease. Ultrasound Obstet Gynecol 2006;28(01):110-116

5 Friedberg MK, Silverman NH, Moon-Grady AJ, et al. Prenatal detection of congenital heart disease. J Pediatr 2009;155(01): 26-31, 31.e1

6 Song MS, Hu A, Dyamenahalli U, et al. Extracardiac lesions and chromosomal abnormalities associated with major fetal heart defects: comparison of intrauterine, postnatal and postmortem diagnoses. Ultrasound Obstet Gynecol 2009;33(05):552-559

7 Copel JA, Cullen M, Green JJ, Mahoney MJ, Hobbins JC, Kleinman $\mathrm{CS}$. The frequency of aneuploidy in prenatally diagnosed congenital heart disease: an indication for fetal karyotyping. Am J Obstet Gynecol 1988;158(02):409-413

8 Wimalasundera RC, Gardiner HM. Congenital heart disease and aneuploidy. Prenat Diagn 2004;24(13):1116-1122

9 Tuuli MG, Dicke JM, Stamilio DM, et al. Prevalence and likelihood ratios for aneuploidy in fetuses diagnosed prenatally with isolated congenital cardiac defects. Am J Obstet Gynecol 2009;201(04): 390.e1-390.e5

10 Mone F, Walsh C, Mulcahy C, et al. Prenatal detection of structural cardiac defects and presence of associated anomalies: a retrospective observational study of 1262 fetal echocardiograms. Prenat Diagn 2015;35(06):577-582

11 Moore JW, Binder GA, Berry R. Prenatal diagnosis of aneuploidy and deletion 22q11.2 in fetuses with ultrasound detection of cardiac defects. Am J Obstet Gynecol 2004;191(06):2068-2073 
12 Ferencz C, Neill CA, Boughman JA, Rubin JD, Brenner JI, Perry LW. Congenital cardiovascular malformations associated with chromosome abnormalities: an epidemiologic study. J Pediatr 1989; 114(01):79-86

13 Russell MW, Chung WK, Kaltman JR, Miller TA. Advances in the understanding of the genetic determinants of congenital heart disease and their impact on clinical outcomes. J Am Heart Assoc 2018;7(06):e006906

14 Jansen FA, Blumenfeld YJ, Fisher A, et al. Array comparative genomic hybridization and fetal congenital heart defects: a systematic review and meta-analysis. Ultrasound Obstet Gynecol 2015;45(01):27-35

15 Pierpont ME, Brueckner M, Chung WK, et al; American Heart Association Council on Cardiovascular Disease in the Young; Council on Cardiovascular and Stroke Nursing; and Council on Genomic and Precision Medicine. Genetic basis for congenital heart disease: revisited: a scientific statement from the American Heart Association. Circulation 2018;138(21):e653-e711

16 Hopkins MK, Dugoff L, Kuller JA. Congenital heart disease: prenatal diagnosis and genetic associations. Obstet Gynecol Surv 2019; 74(08):497-503

17 International Society of Ultrasound in Obstetrics \#38. Cardiac screening examination of the fetus: guidelines for performing the "basic" and "extended basic" cardiac scan. Ultrasound Obstet Gynecol 2006;27(01):107-113

18 Lee W, Allan L, Carvalho JS, et al; ISUOG Fetal Echocardiography Task Force. ISUOG consensus statement: what constitutes a fetal echocardiogram? Ultrasound Obstet Gynecol 2008;32(02):239-242

19 Hunter S, Heads A, Wyllie J, Robson S. Prenatal diagnosis of congenital heart disease in the northern region of England: benefits of a training programme for obstetric ultrasonographers. Heart 2000;84(03):294-298

20 Wren C, Richmond S, Donaldson L. Temporal variability in birth prevalence of cardiovascular malformations. Heart 2000;83(04): 414-419

21 van Velzen CL, Clur SA, Rijlaarsdam ME, et al. Prenatal diagnosis of congenital heart defects: accuracy and discrepancies in a multicenter cohort. Ultrasound Obstet Gynecol 2016;47(05): 616-622

22 Yu Z, Xi Y, Ding W, et al. Congenital heart disease in a Chinese hospital: pre- and postnatal detection, incidence, clinical characteristics and outcomes. Pediatr Int 2011;53(06):1059-1065

23 Ozbarlas N, Erdem S, Küçükosmanoğlu O, et al. Prevalence and distribution of structural heart diseases in high and low risk pregnancies. Anadolu Kardiyol Derg 2011;11(02):125-130

24 Lee JE, Jung KL, Kim SE, et al. Prenatal diagnosis of congenital heart disease: trends in pregnancy termination rate, and perinatal and 1-year infant mortalities in Korea between 1994 and 2005. J Obstet Gynaecol Res 2010;36(03):474-478

25 Clur SA, Van Brussel PM, Mathijssen IB, Pajkrt E, Ottenkamp J, Bilardo CM. Audit of 10 years of referrals for fetal echocardiography. Prenat Diagn 2011;31(12):1134-1140

26 Dolk H, Loane M, Garne EEuropean Surveillance of Congenital Anomalies (EUROCAT) Working Group. Congenital heart defects in Europe: prevalence and perinatal mortality, 2000 to 2005. Circulation 2011;123(08):841-849

27 Breckpot J, Tranchevent LC, Thienpont B, et al. BMPR1A is a candidate gene for congenital heart defects associated with the recurrent 10q22q23 deletion syndrome. Eur J Med Genet 2012;55 (01):12-16

28 Gaussin V, Van de Putte T, Mishina Y, et al. Endocardial cushion and myocardial defects after cardiac myocyte-specific conditional deletion of the bone morphogenetic protein receptor ALK3. Proc Natl Acad Sci U S A 2002;99(05):2878-2883

29 Gaussin V, Morley GE, Cox L, et al. Alk3/Bmpr1a receptor is required for development of the atrioventricular canal into valves and annulus fibrosus. Circ Res 2005;97(03):219-226

308 p23 deletion syndrome, Unique 2013. Rare Chromosome Disorder Support Group, Version 2,1 (SW) 2013

31 Wat MJ, Shchelochkov OA, Holder AM, et al. Chromosome 8p23.1 deletions as a cause of complex congenital heart defects and diaphragmatic hernia. Am J Med Genet A 2009;149A(08):1661-1677

32 Digilio MC, Angioni A, Giannotti A, Dallapiccola B, Marino B. Truncus arteriosus and duplication 8q. Am J Med Genet A 2003; $121 \mathrm{~A}(01): 79-81$

33 Sujansky E, Smith ACM, Prescott KE, Freehauf CL, Clericuzio C, Robinson A. Natural history of the recombinant (8) syndrome. Am J Med Genet 1993;47(04):512-525

34 So J, Stockley T, Stavropoulos DJ. Periventricular nodular heterotopia and transverse limb reduction defect in a woman with interstitial 11q24 deletion in the Jacobsen syndrome region. Am J Med Genet A 2014;164A(02):511-515

35 Guerin A, Stavropoulos DJ, Diab Y, et al. Interstitial deletion of 11q-implicating the KIRREL3 gene in the neurocognitive delay associated with Jacobsen syndrome. Am J Med Genet A 2012; 158A(10):2551-2556

36 Tyson C, Qiao Y, Harvard C, et al. Submicroscopic deletions of 11q24-25 in individuals without Jacobsen syndrome: re-examination of the critical region by high-resolution array-CGH. Mol Cytogenet 2008;1:23

37 Coldren CD, Lai Z, Shragg P, et al. Chromosomal microarray mapping suggests a role for BSX and Neurogranin in neurocognitive and behavioral defects in the 11q terminal deletion disorder (Jacobsen syndrome). Neurogenetics 2009;10(02):89-95

38 Maruani A, Huguet G, Beggiato A, et al. 11q24.2-25 microrearrangements in autism spectrum disorders: relation to brain structures. Am J Med Genet A 2015;167A(12):3019-3030

39 Grossfeld PD, Mattina T, Lai Z, et al. The 11q terminal deletion disorder: a prospective study of 110 cases. Am J Med Genet A 2004;129A(01):51-61

40 Zhan Y, Brown C, Maynard E, et al. Ets-1 is a critical regulator of Ang II-mediated vascular inflammation and remodeling. J Clin Invest 2005;115(09):2508-2516

41 Davidson B, Shi W, Beh J, Christiaen L, Levine M. FGF signaling delineates the cardiac progenitor field in the simple chordate, Ciona intestinalis. Genes Dev 2006;20(19):2728-2738

42 Alvarez AD, Shi W, Wilson BA, Skeath JB. pannier and pointedP2 act sequentially to regulate Drosophila heart development. Development 2003;130(13):3015-3026

43 Ye M, Coldren C, Liang X, et al. Deletion of ETS-1, a gene in the Jacobsen syndrome critical region, causes ventricular septal defects and abnormal ventricular morphology in mice. Hum Mol Genet 2010;19(04):648-656

44 Gao Z, Kim GH, Mackinnon AC, et al. Ets1 is required for proper migration and differentiation of the cardiac neural crest. Development 2010;137(09):1543-1551 